\title{
熱水噴出域で観察される魚類：その生態と化学合成生物群集への捕食効果
}

\section{Fish Fauna Observed at Hydrothermal Vents: Introduction to its Ecology and Effects of Predation on Hydrothermal Vent Communities}

\author{
末次貴志子 \\ 東京大学海洋研究所。广 164-8639 東京都中野区南台 1-15-1 \\ Kishiko SUETSUGU \\ Ocean Research Institute, University of Tokyo, 1-15-1 Minamidai, Nakano-ku, Tokyo 164-8639, Japan
}

\begin{abstract}
Photographs and observations from submersibles have established the presence of deep-sea fish living around hydrothermal vents, but the difficulty in sampling these mobile fish from submersibles has restricted studies about their biology and ecology. About 25 families of deep-sea fish have been observed at hydrothermal vents around the world, with some species appearing to be found only at hydrothermal vents, and others commonly being observed in the deep-sea worldwide. However it is difficult to determine if there are many endemic species at hydrothermal vents. Studies on the food habits of some deep-sea fish species have found that some types of sessile invertebrate in hydrothermal vent communities are important components in their diets. This suggests that there are predator-prey interactions between these fish and the hydrothermal vent fauna, and recent studies have indicated that predation by large mobile predators, such as fish and crabs, can influence the structure of hydrothermal vent communities directly and indirectly. Further studies are needed to clarify the species composition and ecology of fish associated with hydrothermal vents and to examine their influence on sessile chemosynthetic communities.
\end{abstract}

Key Words: deep-sea fish, hydrothermal vents, predation.

\section{はじめに}

熱水噴出域や泠湧水域周辺の生物相の研究には無人探査 機・潜水調查船が多用されてきた (Hessler et al. 1988; Tunnicliffe 1991; Hashimoto et al. 1995). その際に撮影された映 像や写真, また目視観察より,これらの場所にはしばしば 魚類が存在することが明らかになっている (Cohen \& Haedrich 1983; Van Dover et al. 1996). 1977 年以来行わ机てき た太平洋の中央海嶺や西部太平洋の背弧海盆拡大軸を中心 とした研究の結果, 熱水噴出域の生物群集については主に 無脊椎動物で詳細な研究がなされてきた (Grassle 1985; Hessler et al. 1988; Tunnicliffe 1991; Hashimoto et al. 1995; Van Dover et al. 1996; Hashimoto et al. 1999, 2001; Ohta \& Kim 2001; Tsurumi \& Tunnicliffe 2001; Fujikura et al. 2002; Kojima 2002; Van Dover et al. 2002). これまで生物相の研 究の対象となった種はいずれも成体が固着性の生活史を持 つものや, 遊泳力が弱く移動範囲が限られるあのであっ た. 一方, 遊泳能力の高い魚類についての研究はごく限ら れたものしかない (Cohen \& Haedrich 1983). この原因と して, 潜水調查船を用いた採集が困難であること, 映像か らの観察では種を明確に同定できない場合が多いことなど

Received 3 Feb. 2003 Accepted 28 Apr. 2003
が挙げられる、また，遊泳能力の高い生物は移動能力があ るため熱水噴出域や冷湧水域付近にとどまっておらず, し たがってその地域に特異的な集団とみなしにくい点が熱水 噴出域における魚類研究をさらに困難にしていると考えら れる.

熱水噴出域は堆積物が少なく地形が複雑でかつ狭い地域 であるため，一般的な大型底生生物採集測器であるトロー ル網を用いた標本採集は事実上不可能である (Cohen \& Haedrich 1983), このため, 熱水噴出域における魚類相の 解明は, 深海カメラを用いた写真や潜水調査船からの観察 が主であり，実際にトラップやスラープガン (吸引式採集 器)などで個体を採集できたのはこの中の一部に限られて いる (Cohen \& Haedrich 1983; Saldanha 1994; Marques \& Porteiro 2000). このような観察方法は, 付着性の生物やあ る程度移動範囲が限られている生物に対しては有効かもし れないが，魚類のように遊泳能力が高い生物に関しては密 度の推定などの定量的な情報が得にくく，個々の観察に基 ついた記録になりがちである。この結果, 熱水噴出域にお ける魚類相の解明は限られた不十分なデー夕に基づいて行 われてきており，魚類などが化学合成生物群集に与える影 響を取り上げた研究が少ない原因となっていると考えられ

る (Cohen \& Haedrich 1983; Micheli et al. 2002).

これまでの化学合成生物群集の研究は環境の特異性に注 目が集まり，環境が生物に与える影響を焦点とした議論が 
なされてきた (Luther et al. 2001)。しかし，生物群集の構 築には生物間の相互作用, すなわち競争, 捕食, 加入など が重要な役割を果たしていることが指摘されている $(\mathrm{Mi}-$ cheli et al. 2002). このような生物間の相互作用を理解する 上で, 深海底において高位の捕食者である深海性魚類は重 要であり, それらが熱水噴出域の生物相に与える影響への 考慮が熱水噴出域の生物群集の理解, ひいては深海生態系 全体の正確な把握には必要不可欠であると考えられる。本 稿ではこれまで熱水噴出域において観察されてきた主な魚 類とその生態に対する知見を簡単にまとめる。 また，熱水 噴出域の生物相に捛ける生物間相互作用に注目した研究例 を挙げ，その重要性について考察する.

\section{熱水噴出域で観察された深海底生魚類}

世界各地の熱水噴出域で見られた魚類の主な観察記録を Table 1 にまとめた。 その結果, 東部太平洋て種数か最も多 かったのはゲンゲ科 Zoarcidae で5種であった。次がフサ イタチウオ科 Bathytidae の 4 種（不明種 2 種を含む）で, トカゲギス科 Halosauridae, ガンギエイ科 Rajidae, アシロ 科 Ophidiidae がそれぞれ 2 種ずつ観察されている。1 種し か観察されなかった科はクサウオ科 Liparidae，セキトリ イワシ科 Alepocephalidae, チゴダラ科 Moridae, ソコダラ 科 Macrouridae であった，一方，西部太平洋，主に日本周 辺で観察された魚類のうち, 最も種数が多かったのはメク ラウナギ科 Myxinidae，ホラアナコ科 Synaphobranchidae (不明種 1 種を含む), ゲンゲ科（不明種 1 種を含む）の 2 種で, トカゲギス科、ウシノシ夕科 Cynoglossidae, ウラ ナイカジカ科 Psychrolutidae はそれぞれ1種ずつしか観察 されなかった，東部太平洋と同じく研究が活発に行われて きた大西洋中央海嶺では, 種数が最も多かった科はンコ夕 ラ科，ホラアナコ科の 4 種で、チゴダラ科、ギンザメ科 Chimeridae が 3 種で続いている. 2 種か観察されたのは, ゲンケ科, カラスザメ科 Etmopteridae であり，1 種のみが 観察されたのは，セキトリイワシ科，トラザメ科 Scyliorhinidae, ソコギス科 Notacanthidae, フサイタチウオ科, フ サカサゴ科 Scorpaenidae, フサアンコウ科 Chaunacidae, ヤセムツ科 Epigonidae，キンメタイ科 Berycidae，オオメマ トゥタイ科 Oreosomatidae, タラ科 Gadidae, ツノザメ科 Squalidae であった。 これらの3 地域に共通して見られた 科はゲンゲ科のみであった。このように，以上の 3 海域で は最も種数が多い科が異なり, 共通した科が少ない。

熱水噴出孔近傍の生物群集における地域間での比較は, Tunnicliffe \& Fowler (1996) により生物群集全体について 行われている. その結果, 生物群集は東部太平洋, 西部太 平洋, 大西洋の 3 地域に大きく分かれ，この傾向は種レべ ル, 属レベルで同じであった。このことは, 地域間におけ る歴史的なプレートの地理的位置やタイミングの違いが熱 水噴出域の全生物群集構造に影響している可能性を示し
た. また，太平洋北東部内で見られる複数の熱水噴出域間 の生物群集を比較した結果, 生物群集間で見られた類似性 と地域間の生息環境の違いとが一致した。しかし，この研 究は各地における別々の観察に基づいており, 各観察では 観察時間や観察総面積の違い, 観察方法が不均一であるこ と，前述したように偶発性が高い観察に基づかざるをえな いことなどの人為的な要因が観察された魚類相の差に反映 されている可能性すある。 また，海域により熱水噴出域の 深度も様々であり, 異なる海域の熱水噴出域を一概に比較 することはできない，これらの要因の影響を考慮した上で も, 熱水噴出域近傍で観察された魚類が東部太平洋, 西部 太平洋, 大西洋で異なり, 共通する科が少なかったことは, 地域間の生息環境の違いが間接的あるいは直接的に魚類相 の違いに関連している可能性が挙げられる. 今後は, 生息 環境や深度など, 様々な環境要因と魚類相の関係について の詳細な研究が必要となるだろう。また，人為的要因を軽 減し, より正確な熱水噴出孔付近の生物相を比較するため には, 遊泳能力の高い生物に関してあ定量的な観察, 採集 が必要不可欠である. 付着性生物, 遊泳能力を持つ生物の 両方に関して定量的な観測測器や方法の開発が重要になっ てくるだろう.

Cohen \& Haedrich (1983) は, Galapagos Rift の熱水噴出 域に見られた魚類相の解明を, 深海カメラシステム, 有人 潜水調査船 Alvin からの目視による観察, 実際の個体採集 加ら行っている. 観察・採集深度は主に $2500 \mathrm{~m}$ である. 観察された種数は, 熱水噴出孔近傍で深海カメラシステム を用いた調查では 9 10 種, 熱水噴出孔で Alvin を用いた 観察からは9〜11 種確認された。このうち共通していた種 はガンギエイ科, ソコダラ科, クサウオ科，ゲンゲ科に属 する 5 種であった，また， 5 個体が実際に採集され，それら はゲンゲ科とソコダラ科が 2 個体ずつ, アシロ科が 1 個体 であった。樑海カメラシステム, Alvin から観察された魚 類の行動から, 観察された種のうちチゴダラ科のカナダダ ラ属を含む多くの種では明らかに熱水噴出孔を避けるよう な行動が見られた. 一方, ソコダラ科の Coryphaenoides anguliceps, ヨロイダラ C. armatus, C. bulbiceps は熱水噴出域 に観察された。また，フサイタチウオ科の Diplacanthopoma sp. は熱水噴出孔域にのみに特異的に見られた。.Cohen \& Haedrich (1983) の研究で観察された種の中には地理的に 広い分布を示すものが多く, その固有性については明確に していない。

数種の魚類については熱水噴出域に特異的に分布するこ とがわかっている. Geistdoerfer (1994a) は大西洋中央海嶺 からゲンゲ科の新種 Pachycara thermophilum を報告してお り，熱水噴出孔付近にのみ生息すると報告している.まだ, マヌス海盆の熱水噴出孔からもゲンゲ科の新種 Pyrolycus manusanus が記載されている (Machida \& Hashimoto 2002). 東部太平洋海膨から採集されたゲンゲ科の Thermarces andersoni については乳酸脱水素酵素が温度, 压力から受ける 
Table 1. List of fish observed at hydrothermal vents

\begin{tabular}{|c|c|c|c|c|}
\hline Location & & Family & Species & Reference \\
\hline \multirow[t]{21}{*}{ East Pacific } & & Zoarcidae & $\begin{array}{l}\text { Thermarces cerberus } \\
\text { Thermarces andersoni }\end{array}$ & $\begin{array}{l}\text { Rosenblatt \& Cohen (1986) } \\
\text { Rosenblatt \& Cohen (1986) }\end{array}$ \\
\hline & Northeast Pacific & Zoarcidae & Pachycara gymnium & Tunnicliffe (1991) \\
\hline & Rose Garden & Bythitidae & & Hessler et al. (1988) \\
\hline & East Pacific Rise & Bythitidae & Bythites hollisi & Shank et al. (1998) \\
\hline & & Liparidae & Careproctus hyaleius & Geistdoerfer (1994b) \\
\hline & & Zoarcidae & Thermarces cerberus & Tunnicliffe (1991) \\
\hline & & & Thermarces andersoni & de Buron et al. $(2000)$ \\
\hline & Galapagos Rift & Alepocephalidae & ?Conocara & Cohen \& Haedrich (1983) \\
\hline & & Bythitidae & & Tunnicliffe (1991) \\
\hline & & & Bythites hollisi & Cohen et al. (1990) \\
\hline & & & Diplacanthopoma sp. & Cohen \& Haedrich (1983) \\
\hline & & Halosauridae & Halosaur (pale) & Cohen \& Haedrich (1983) \\
\hline & & & Halosaur (dark) & Cohen \& Haedrich (1983) \\
\hline & & Macrouridae & Coryphaenoides anguliceps & Cohen \& Haedrich (1983) \\
\hline & & Moridae & Antimora (rostrata?) & Cohen \& Haedrich (1983) \\
\hline & & Ophidiidae & Acanthonus armatus & Cohen \& Haedrich (1983) \\
\hline & & & Spectrunculus grandis & Cohen \& Haedrich (1983) \\
\hline & & Rajidae & Skate (broad snout) & Cohen \& Haedrich (1983) \\
\hline & & & Skate (narrow snout) & Cohen \& Haedrich (1983) \\
\hline & & Zoarcidae & Zoarcid (large) & Cohen \& Haedrich (1983) \\
\hline & & & Zoarcid (small) & Cohen \& Haedrich (1983) \\
\hline \multirow[t]{11}{*}{ West Pacific } & & Synaphobranchidae & Thermobiotes mytilogeiton & Meunies \& Geistdoerfer (1991) \\
\hline & Iheya Ridge & Halosauridae & Aldrovandia affinis & Ohta \& Kim (2001) \\
\hline & & Myxinidae & Eptatretus okinoseanus & Ohta \& Kim (2001) \\
\hline & & Synaphobranchidae & Synaphobranchid & Ohta \& Kim (2001) \\
\hline & Minami-Ensui Knoll & Cynoglossidae & Symphurus cf. orientalis & Hashimoto et al. (1995) \\
\hline & & Myxinidae & Eptatretus okinoseanus & Hashimoto et al. (1995) \\
\hline & & & Myxine garmani & Hashimoto et al. (1995) \\
\hline & & Psychrolutidae & Psychrolutes inermis & Hashimoto et al. (1995) \\
\hline & & Zoarcidae & Zoarcidae gen. sp. & Hashimoto et al. (1995) \\
\hline & Manus Basin & Zoarcidae & Pyrolycus manusanus & Machida \& Hashimoto (2002) \\
\hline & Lau Basin & Synaphobranchidae & Thermobiotes mytilogeiton & Desbruyeres \& Segonzac (1997) \\
\hline \multirow[t]{29}{*}{ Atlantic } & Mid-Atlantic Ridge & Macrouridae & Coryphaenoides armatus & Tunnicliffe (1991) \\
\hline & & Synaphobranchidae & Haptenchelys texis & Parin (1995) \\
\hline & & Zoarcidae & Pachycara thermophilum & Geistdoerfer (1994a) \\
\hline & & & Aff. Thermarces & Tunnicliffe (1991) \\
\hline & Mid-Atlantic Ridge, & Epigonidae & Epigonus telescopus & Desbruyeres \& Segonzac (1997) \\
\hline & Next to Menez-Gwen & Berycidae & Beryx splendens & Desbruyeres \& Segonzac (1997) \\
\hline & & Chaunacidae & Chaunax sp. & Desbruyeres \& Segonzac (1997) \\
\hline & & Moridae & Mora moro & Desbruyeres \& Segonzac (1997) \\
\hline & & Scorpaenidae & Tranchyscorpia cristulata echinata & Desbruyeres \& Segonzac (1997) \\
\hline & Menez-Gwen & Etmopteridae & Etmopterus pusillus & Desbruyeres \& Segonzac (1997) \\
\hline & Lucky Strike & Alepocephalidae & Alepocephalidae gen. sp. & Marques \& Almeida (2000) \\
\hline & & Bythitidae & Cataetyx laticeps & Desbruyeres \& Segonzac (1997) \\
\hline & & Chimaeridae & Hydrolagus affinis & Desbruyeres \& Segonzac (1997) \\
\hline & & & Hydrolagus pallidus & Desbruyeres \& Segonzac (1997) \\
\hline & & & Hydrolagus mirabilis & Saldanha (1994) \\
\hline & & Etmopteridae & Etmopterus princeps & Desbruyeres \& Segonzac (1997) \\
\hline & & Lotidae & Gaidropsarus sp. & Desbruyeres \& Segonzac (1997) \\
\hline & & Macrouridae & Caelorinchus cf. labiatus & Desbruyeres \& Segonzac (1997) \\
\hline & & & Coryphaenoides armatus & Desbruyeres \& Segonzac (1997) \\
\hline & & & Coryphaenoides macrocephalus & Desbruyeres \& Segonzac (1997) \\
\hline & & & Macrourinae gen. sp. & Desbruyeres \& Segonzac (1997) \\
\hline & & Moridae & Lepidion schmidti? & Desbruyeres \& Segonzac (1997) \\
\hline & & Notacanthidae & Polyacanthonotus cf. rissoanus & Desbruyeres \& Segonzac (1997) \\
\hline & & Oreosomatidae & Neocyttus helgae & Desbruyeres \& Segonzac (1997) \\
\hline & & Scyliorhinidae & Apristurus maderensis & Desbruyeres \& Segonzac (1997) \\
\hline & & Squalidae & Centroscymnus coelolepis & Desbruyeres \& Segonzac (1997) \\
\hline & & Synaphobranchidae & Ilyophis blachei & Desbruyeres \& Segonzac (1997) \\
\hline & & & Simenchelys parasiticus & Desbruyeres \& Segonzac (1997) \\
\hline & & & Synaphobranchus kaupi & Desbruyeres \& Segonzac (1997) \\
\hline
\end{tabular}


影響について調べられている，その結果，熱水噴出孔付近 に生息するこの種の醉素活性は, 生息する環境の压力下で は温度による影響を受けにくいことが明らかとなってお り,これは熱水噴出孔で生息するための適応ではないかと 考えられている (Dahlhoff et al. 1990). また, 同様に東部太 平洋の熱水噴出域で採集されたゲンゲ科の Thermarces cerberus では，一般の深海底に生息する魚類よりす高い代謝 率が見られた。浅海の近縁種の代謝率と似ていることか ら,この種は栄養の豊富な熱水噴出域に生息するために高 い代謝率老示すと考えられている (Hand \& Somero 1983). このように熱水噴出域には，その近傍にのみに生息すると 考えられる種と，広域的な分布を示す種の両方が見られ る.このことは, 熱水噴出域にも一般的な深海底にも共通 して存在する移動能力の高い魚類がいる可能性を示してい ろ.

\section{化学合成生物群集内の生物間相互作用}

熱水噴出域で観察される魚類の採集は難しく,これまで 採集された個体数は多くない。しかし，それらの胃内容物 についての報告がいらつかある. 大西洋中央海嶺で報告さ れたゲンゲ科の P. thermophilum は熱水噴出孔に生息する 2 種の十脚長尾類の Rimicaris exoculata, Chorocaris chacei を捕食していた (Geistdoerfer 1994a). 大西洋中央海嶺の Lucky Strikeで採集されたギンザメ科の Hydrolagus mirabilis は十脚類や端脚類を捕食しており, 熱水噴出域に特異 的に生息する生物を捕食している証拠は得られなかった が，フサイタチウオ科の Cataetyx laticeps の胃内容物には 熱水噴出域に生息する Bresiliidae 科のエビ類が含まれてい た. また, 腸の中にもエビ類と軟体動物の凯, 岩の破片が 含まれていた (Saldanha 1994). 同じく大西洋中央海嶺で 採集されたギンザメ科の Hydrolagus affinis の胃から，熱水 噴出域に生息する二枚貝の 1 種 Bathymodiolus thermophilus の貝㪍破片が見つかった (Marques \& Porteiro 2000). 西部太平洋では, 中部沖縄トラフから採集されたゲンゲ科 の胃から十脚類の Lebbeus washingtonianus が見つかってい る (Hashimoto et al. 1995). Lebbeus washingtonianus の分布 は熱水噴出域に限られてはいないが, 熱水噴出域に多く見 られる十脚類である。 また, マヌス海盆で採集されたゲン ゲ科の Pyrolycus manusanus の胃内容物に Bresiliidae 科のエ ビ類が含まれていたという報告がある (Machida \& Hashimoto 2002). 東部太平洋の熱水噴出域で採集されたゲンゲ 科の Thermarces cerberus の胃内容物からは, 潜水調查船 Alvin が壊したと思われる八オリムシ Riftia pachyptila の栄 養体部か観察されている (Rosenblatt \& Cohen 1986). 以上 の報告から, 熱水噴出域で見られる魚類の中には, 化学合 成生物群集の構成種を捕食するものがいることが示され た. 魚類は移動能力が高いため, 生産性が高い化学合成生 物群集から生産性の低い一般的な深海へのエネルギー伝達
の一つの経路として重要であると考えられる．栄養段階を 解析する方法としては, 同位体を用いた研究が無春椎動物 や中層性生物に扔いて行わ扎ている (Burd et al. 2002; Van Dover 2002). 胃内容物の解析だけではなく，このような方 法を用いることで熱水噴出孔に生息する生物間の捕食一被 食関係や栄養段階を明確にできると考えられる.

熱水噴出孔付近の環境は独特で変化に富んでいるため, 化学合成生物群集やそれを構成している生物の生態を研究 する際には環境要因か注目され，生物間相互作用はあまり 注目されてこなかった (Luther et al. 2001). しかし近年, East Pacific Rise (EPR) て熱水噴出域の化学合成生物群集 に対する捕食の影響についての研究が行わ机た (Micheli et al. 2002). 捕食者が化学合成生物群集の構造や種の加入に 及ぼす影響, 熱水噴出域からの距離や環境勾配の変化に 従った捕食の効果を明らかにすることを目的として, ケ一 ジを用いた捕食者除去実験が行われた。 また，捕食者の選 好性を調へるため，熱水噴出域に生息するハオリムシ Riftia pachyptila, シンカイヒバリガイ Bathymodiolus thermophilus，カサガイ科腹足類の Lepetodrilus elevatus，上一般の 深海底に生息する二枚貝 Megapitaria squaludae を並へ，そ れらが捕食される様子を深海カメラで撮影し，採集できた 捕食者に関しては胃内容物を解析した。捕食者除去実験の 結果, 最屯熱水噴出孔に近い場所では, 小型で移動能力の ある腹足類や端脚類の生物量が増加したが, 付着性生物の 生物量は減少した。よって, 環境が最も極端であるが生産 量が最も高い熱水噴出孔付近では, 捕食による生物間相互 作用が直接的, 間接的に群集構造に影響を与えていること が示唆された。一方，力メラを用いた観察や胃内容物の解 析から，甲殼類之並んで普通に見られる捕食者であったゲ ンゲ科の Thermarces cerberus が, 化学合成生物群集を形成 していた小型のグレーザーである腹足類の Cyathermia naticoides やフネカサガイ科の Lepetodorilus elevantus, L. pustulosus 捕食していることが分かった。 また， EPRの軸に 沿って地理的に数 $\mathrm{km}$ 離れた 3 ヶ所の熱水噴出域でも同様 の傾向が見られたことから, 熱水噴出域の生物群集におけ る捕食者の効果が一般的に存在することが示唆された。こ れらのことから，環境勾配などの非生物的要因だけでな く, 捕食-被食関係に見られる生物間相互作用が熱水噴出 域の付着性生物群集の形成に関係していることが考えられ ろ.

熱水噴出域の研究では，バクテリアから付着性生物への エネルギー伝達が注目されており, 移動能力が高い捕食者 が付着性生物に与える影響に注目した研究は少なかった (Tunnicliffe 1991). しかし, この点に注目した Micheli et al. (2002) の研究は, 熱水噴出域の生物群集が甲殻類や魚類に 捕食されること, それにより生物群集構造が変化すること を現場における操作実験で明らかにした，このことは，熱 水噴出域の生物群集構造やその維持機構を考える上で魚類 が大きな影響を与えている可能性を示唆している。 また， 
実験期間が 5 ヶ月，8ヶ月と短かったにもかかわらず群集 に明瞭な变化が見られたことから, 熱水噴出域の生物群集 はダイナミックに変化している可能性が考えられる.

熱水嘖出孔の環境は時間的に変動が大きく，生物群集も それに沿って変化することが知られている (Hessler et al. 1988; Tsurumi \& Tunnicliffe 2001).このような変化は，捕 食一被食関係のような生物間相互作用に影㛭を及代し，群 集構造の形成機構を変化させる可能性があるだろう。 た，熱水の温度や含まれる様々なイオン，その浱度などの 熱水噴出域の物理的性質により生物群集が受ける影響も 様々であろう，熱水噴出域付近の魚類研究は記述的なもの が多く, 生態や他生物との関わりに着目した研究は少な い，今後は，異なる性質を持つ熱水顛出域で，非生物的要 因だけでなく捕食などの生物間相互作用にも注目した研究 が必要となってくるだろう，また，時系列に沿って熱水噴 出域の生物群集の生物間相互作用や環境要因との関わりを 明らかにしていくことで, 群集の形成機構の解明に対する 理解が深まることが期待される.

辞：本稿を校閲して頂いた太田秀教授，小島茂明助教授，鴄 永元裕助手，山口成能博士，並びに英語部分を校閲していただい た M. J. Miller 博士に厚く御礼申し上げます、また，本稿を執筆す る機会を与えてくださった大越和加博士，藤倉克則博士に深く感 謝致します。

\section{引用文辣}

Burd, B. J., R. E. Thomson and S. E. Calvert 2002. Isotopic composition of hydrothermal epiplume zooplankton: evidence of enhanced carbon recycling in the water column. Deep-Sea Research I, 49: $1877-1900$.

Cohen, D. M. and R. L. Haedrich 1983. The fish fauna of the Galapagos thermal vent region. Deep-Sea Research, 30: 371-379.

Cohen, D. M., R. H. Rosenblatt and H. G. Moser 1990. Biology and description of a bythitid fish from deep-sea thermal vents in the tropical eastern Pacific. Deep-Sea Research, 37(2): 267-283.

de Buron, I., J. L. Hundley and M. Segonzac 2000. Report of gravid female acanthocephalans in zoarcid fish from EPR $13^{\circ} \mathrm{N}$ and of a potential amphipod intermediate host for this parasitic worm. InterRidge News, 9(2): 14-15.

Dahlhoff, E., S. Schneidemann and G. N. Somero 1990. Pressuretemperature interactions on $\mathrm{M}_{4}$-lactate dehydrogenases from hydrothermal vent fishes: evidence for adaptation to elevated temperatures by the zoarcid Thermarces andersoni, but not by the bythitid, Bythites hollisi. Biological Bulletin, 179: 134-139.

Desbruyeres, D. and M. Segonzac (eds.) 1997. Handbook of DeepSea Hydrothermal Vent Fauna. IFREMER, 279 pp.

Fujikura, K., J. Hashimoto and T. Okutani 2002. Estimated population densities of megafauna in two chemosynthesis-based communities: a cold seep in Sagami Bay and a hydrothermal vent in Okinawa Trough. Benthos Research, 57(1): 21-30.

Kojima, S. 2002. Deep-sea chemosynthesis-based communities in the northwestern Pacific. Journal of Oceanography, 58(2): 343-363.

Geistdoerfer, P. 1994a. Pachycara thermophilum, une nouvelle espèce de poisson Zoarcidae des sites hydrothermaux de la dorsale médio-Atlantique. Cybium, 18(2): 109-115.
Geistdoerfer, P. 1994b. Careproctus hyaleius, nouvelle espèce de poisson Cyclopteridae (Liparinae) de l'écosystème hydrothermal de la dorsale de l'Ocèan Pacifique oriental $\left(13^{\circ} \mathrm{N}\right)$. Cybium, 18(3): 325-333.

Grassle, J.F. 1985. Hydrothermal vent animals: distribution and biology. Science, 229: 713-717.

Hand, S. C. and G. N. Somero 1983. Energy metabolism pathways of hydrothermal vent animals: adaptations to a food-rich and sulfide-rich deep-sea environment. Biological Bulletin, 165: 167181.

Hashimoto, J., S. Ohta, A. Fiala-Medioni, J.-M. Auzende, S. Kojima, M. Segonzac, Y. Fujiwara, J. C. Hunt, K. Gera, T. Miura, T. Kikuchi, T. Yamaguchi, T. Toda, H. Chiba, S. Tsuchida, J. Ishibashi, K. Henry, M. Zbinden, A. Pruski, A. Inoue, H. Kobayashi, J.-L. Birrien, J. Naka, T. Yamanaka, C. Laporte, K. Nishimura, C Yeats, S. Malagun, P. Kia, M. Oyaizu and T. Katayama 1999. Hydrothermal vent communities in the Manus Basin. Papua New Guinea: results of the BIOACCESS cruises '96 and '98. Inter Ridge News, 8(2): 12-18.

Hashimoto, J., S. Ohta, T. Gamo, H. Chiba, T. Yamaguchi, S. Tsuchida, T. Okudaira, H. Watabe, T. Yamanaka and M. Kitazawa 2001. First hydrothermal vent communities from the Indian Ocean discovered. Zoological Science, 18(5): 717-721.

Hashimoto, J., S. Ohta, K. Fujikura and T. Miura 1995. Microdistribution pattern and biogeography of the hydrothermal vent communities of the Minami-Ensui Knoll in the Mid-Okinawa Trough, Western Pacific. Deep-Sea Research I, 42(4): 577-598.

Hessler, R. R., W. M. Smithey, M. A. Boudrias, C. H. Keller, R. A. Lutz and J. J. Childress 1988. Temporal change in megafauna at the Rose Garden hydrothermal vent (Galapagos Rift; eastern tropical Pacific). Deep-Sea Research, 35: 1681-1709.

Luther III, G. W., T. F. Rozen, M. Taillefert, D. B. Nuzzlo, C. Di Meo, T. M. Shank, R. A. Lutz and S. C. Cary 2001. Chemical speciation drives hydrothermal vent ecology. Nature, 410: 813816.

Machida, Y. and J. Hashimoto 2002. Pyrolycus manusanus, a new genus and species of deep-sea eelpout from a hydrothermal vent field in the Manus Basin, Papua New Guinea (Zoarcidae, Lycodinae). Ichthyological Research, 49: 1-6.

Marques, A. and A. J. Almeida 2000. Fishes from the Lucky Strike hydrothermal vent field and the surrounding deep-sea environment: Crista 3 Cruise results. Inter Ridge News, 9(2): 16-17.

Marques, A. and F. Porteiro 2000. Hydrothermal vent mussel $B a$ thymodiolus sp. (Mollusca: Mytilidae): Diet item of Hydrolagus affinis (Pisces: Chimaeridae). Copeia, 2000(3): 806-807.

Meuneir, F. J. and P. Geistdoerfer 1991. Anatomie de la ceinture pectorale de Thermobiotes mytilogeiton (Synaphobranchidae), Anguilliforme des sources hydrothermales du Pacifique occidental. Cybium, 15(1): 83-87.

Micheli, F., C. H. Peterson, L. S. Mullineaux, C. R. Fisher, S. W. Mills, G. Sancho, G. A. Johnson and H. S. Leihan 2002. Predation structures communities at deep-sea hydrothermal vents. Ecological Monographs, 72(3): 365-382.

Ohta, S. and D. Kim 2001. Submersible observations of the hydrothermal vent communities on the Iheya Ridge, Mid Okinawa Trough, Japan. Journal of Oceanography, 57(6): 663-677.

Parin, N. V. 1995. Deep-sea fishes, Haptenchelys texis (Synaphobranchidae) and Pachycara thermophilum (Zoarcidae) from the Broken Spur hydrothermal vent field (Mid-Atlantic Ridge). Journal of Ichthyology, 35(9): 328-332.

Rosenblatt, R. H. and D. M. Cohen 1986. Fishes living in deepsea 
thermal vents in the tropical eastern Pacific, with descriptions of a new genus and two new species of eelpouts (Zoarcidae). Transactions of the San Diego Society of Natural History, 21(4): 71-79.

Saldanha, L. 1994. Fishes observed and collected during the Alvin dives at the Lucky Strike thermal vent site (Mid-Atlantic Ridge1993). Cybium, 18(4): 460-462.

Shank, T. M., D. J. Fornari, K. L. Von Damm, M. D. Lilley, R. M. Haymon and R. A. Lutz 1998. Temporal and spatial patterns of biological community developed at nascent deep-sea hydrothermal vents $\left(9^{\circ} 50^{\prime} \mathrm{N}\right.$, East Pacific Rise). Deep-Sea Research II, 45: 465515.

Tsurumi, M. and V. Tunnicliffe 2001. Characteristics of a hydrothermal vent assemblage on a volcanically active segment of Juan de Fuca Ridge, northeast Pacific. Canadian Journal of Fisheries and Aquatic Science, 58: 530-542.

Tunnicliffe, V. 1991. The biology of hydrothermal vents: ecology and evolution. Oceanography and Marine Biology: an Annual Review, 29: 319-407.

Tunnicliffe, V. and M. R. Fowler 1996. Influence of sea-floor spreading on the global hydrothermal vent fauna. Nature, 379: 531-533.

Van Dover, C. L., C. R. German, K. G. Speer, L. M. Parson and R. C. Vrijenhoek 2002. Evolution and biogeography of deep-sea and seep invertebrates. Science, 295; 1253-1257.

Van Dover, C. L., D. Desbruyeres, M. Segonzac, T. Comtet, L. Saldanha, A. Fiala-Medioni and C. Langmuir 1996. Biology of the Luckey Strike hydrothermal field. Deep-Sea Research I, 43(9): 1509-1529. 